\title{
Dynamic regulation of NMDAR function in the adult brain by the stress hormone corticosterone
}

\author{
Yiu Chung Tse ${ }^{1+}$, Rosemary C. Bagot ${ }^{1+\ddagger}$ and Tak Pan Wong ${ }^{1,2,3 *}$ \\ ${ }^{1}$ Neuroscience Division, Douglas Mental Health University Institute, McGill University, Montreal, QC, Canada \\ 2 Department of Psychiatry, McGill University, Montreal, OC, Canada \\ ${ }^{3}$ Department of Pharmacology and Therapeutics, McGill University, Montreal, QC, Canada
}

Edited by:

Harmen J. Krugers, Universiteit van Amsterdam, Netherlands

Reviewed by:

Amiel Rosenkranz, RFUMS -

Chicago Medical School, USA

Graziella DiCristo, University of

Montreal, Canada

\section{*Correspondence:}

Tak Pan Wong, Douglas Mental

Health University Institute,

6875 LaSalle Blvd., Montreal,

OC H4H 1R3, Canada.

e-mail: tak.wong@mcgill.ca

${ }^{t}$ These authors contributed equally to this work.

${ }^{\ddagger}$ Present Address:

Fishberg Department of

Neuroscience, Mount Sinai School of Medicine, New York, NY 10029, USA.
Stress and corticosteroids dynamically modulate the expression of synaptic plasticity at glutamatergic synapses in the developed brain. Together with alpha-amino-3-hydroxymethyl-4-isoxazole propionic acid receptors (AMPAR), N-methyl-D-aspartate receptors (NMDAR) are critical mediators of synaptic function and are essential for the induction of many forms of synaptic plasticity. Regulation of NMDAR function by cortisol/corticosterone (CORT) may be fundamental to the effects of stress on synaptic plasticity. Recent reports of the efficacy of NMDAR antagonists in treating certain stress-associated psychopathologies further highlight the importance of understanding the regulation of NMDAR function by CORT. Knowledge of how corticosteroids regulate NMDAR function within the adult brain is relatively sparse, perhaps due to a common belief that NMDAR function is stable in the adult brain. We review recent results from our laboratory and others demonstrating dynamic regulation of NMDAR function by CORT in the adult brain. In addition, we consider the issue of how differences in the early life environment may program differential sensitivity to modulation of NMDAR function by CORT and how this may influence synaptic function during stress. Findings from these studies demonstrate that NMDAR function in the adult hippocampus remains sensitive to even brief exposures to CORT and that the capacity for modulation of NMDAR may be programmed, in part, by the early life environment. Modulation of NMDAR function may contribute to dynamic regulation of synaptic plasticity and adaptation in the face of stress, however, enhanced NMDAR function may be implicated in mechanisms of stress-related psychopathologies including depression.

Keywords: electrophysiology, synaptic plasticity, stress, receptor trafficking, corticosteroid receptor, learning and memory

\section{INTRODUCTION}

In developed countries such as Canada, around three quarters of the adult population experience moderate levels of stress (Statistics Canada, 2002). As a potent modulator of memory (McEwen and Sapolsky, 1995; Sandi and Pinelo-Nava, 2007), stress is implicated in the associated cognitive impairment in depressive disorders (Muscatell et al., 2009). However, stress does not always impair memory. Indeed, stress is believed to be crucial to the immutable storage of traumatic memories in post-traumatic stress disorder (PTSD) (Vanitallie, 2002). Investigating how stress exerts both facilitatory and suppressive effects on memory could improve our understanding of abnormal memory function in stress-related psychiatric disorders. At the cellular level, memory is established via persistent alterations in the strength of synaptic transmission through a collection of cellular processes known as synaptic plasticity. In parallel with its impact on memory, stress can both facilitate and suppress synaptic plasticity via the actions of the stress hormone cortisol, or corticosterone (CORT) in rodents. Thus, investigating the mechanisms underlying the impact of CORT on synaptic plasticity could help reveal the physiological basis of cognitive effects of stress.
Activation of glutamate receptors, including AMPA ( $\alpha$-amino3-hydroxy-5-methylisoxazole-4-propionic acid) and NMDA subtypes (N-methyl-D-aspartate), is instrumental to the formation and maintenance of synaptic plasticity such as long-term potentiation (LTP) and long-term depression (LTD) (Bliss and Collingridge, 1993; Bear and Abraham, 1996; Malinow and Malenka, 2002). Glutamate receptors could be important cellular targets for stress and CORT to regulate synaptic plasticity in the adult brain. Indeed, at least in developing brain tissue, CORT regulates the trafficking properties of AMPA receptor [AMPAR (Groc et al., 2008; Martin et al., 2009)]. Until recently, NMDA receptor (NMDAR) was widely believed to be highly stable in the adult brain. Recent findings from our laboratory revealed CORT-induced plastic changes in both the function and subunit composition of NMDAR. Given that NMDAR plays critical roles in synaptic plasticity, these findings illustrate a novel mechanism for stress to regulate synaptic plasticity. We also found that CORT-induced changes in NMDAR in adulthood can be programmed by early life adversity such as low maternal care. Since early life stress strongly associates with an increased vulnerability to psychiatric disorders like depression (Kessler et al., 
1997; McLaughlin et al., 2010), our findings support an emerging view that alteration of the plastic properties of NMDAR is a key biological substrate of stress-related brain disorders.

The purpose of this review is, therefore, to summarize findings from our laboratory concerning the influence of CORT on NMDAR function in the adult brain. We first discuss the current understanding of the impact of CORT on hippocampal synaptic plasticity. Next, we describe recent findings demonstrating that plastic changes of NMDAR function after CORT exposure regulate synaptic plasticity in the adult brain. Finally, we summarize findings showing that the impact of CORT on NMDAR function in adulthood can be programmed by early life experience in the form of maternal care.

\section{CORT AND SYNAPTIC PLASTICITY}

CORT is a pleiotropic hormone that regulates cardiovascular, immunologic, metabolic, and neurologic functions (Sapolsky et al., 2000). The cellular actions of CORT are mediated by two types of corticosteroid receptors: low affinity glucocorticoid receptors (GRs) and high-affinity mineralocorticoid receptors (MRs) (Reul and de Kloet, 1985; Joels, 2001). Both GR and MR can be found in the cytosol and function as transcription factors that alter gene expression. Recent findings also suggest the presence of membrane-associated GRs and MRs to mediate fast-acting (<30 min) non-genomic actions of CORT (Prager and Johnson, 2009). Under basal conditions, plasma (Atkinson et al., 2006) and hippocampal (Droste et al., 2008) CORT levels follow a circadian rhythm with a nadir around the start of the light cycle. During the light cycle and part of the dark cycle, CORT levels also show an ultradian pattern (1 cycle/h). During ultradian peaks hippocampal CORT levels reach as high as $15 \mathrm{nM}$ (Droste et al., 2008). Stress also significantly raises the levels of hippocampal CORT. For example, a $15 \mathrm{~min}$ period of forced swimming increases hippocampal CORT to approximately $100 \mathrm{nM}$ for around $30 \mathrm{~min}$ (Droste et al., 2009). CORT exhibits both facilitating and suppressing effects on memory function and hippocampal synaptic plasticity. LTP (Bliss and Lomo, 1973; Bliss and Collingridge, 1993) and LTD (Dudek and Bear, 1992; Bear and Abraham, 1996) are two forms of synaptic plasticity which are regarded as cellular models of learning and memory (Bliss and Collingridge, 1993; Martin et al., 2000). The impact of CORT on synaptic plasticity depends on various factors, which will be discussed below.

\section{LEVEL OF CORT}

Basal levels of CORT are important for memory function such that insufficient CORT (e.g., in adrenalectomized animals) results in impaired LTP (Diamond et al., 1992) and memory (Vaher et al., 1994). These promnesic influences of CORT are likely mediated by high affinity MRs, since LTP is enhanced by MR agonists (Pavlides et al., 1994, 1996; Rey et al., 1994), and stress-induced facilitation of LTP is blocked by MR antagonists (Korz and Frey, 2003; Avital et al., 2006). Exposure to CORT at stress levels, which activates both MRs and GRs, usually results in impairment of memory. Most of these negative impacts were observed hours after CORT application (Pavlides et al., 1995, 1996; Krugers et al., 2005; Wiegert et al., 2005), suggesting the requirement of GR-induced genomic mechanisms (Tsai and O'Malley, 1994). The detrimental impacts of CORT on memory functions could be partly attributed to GR-mediated LTP suppression. LTP is suppressed by GR agonists (Pavlides et al., 1995) and stress-induced inhibition of LTP is blocked by GR antagonists (Rey et al., 1994; Avital et al., 2006). These findings highlight the inverted-U shape relationship between LTP formation and CORT concentration (Diamond et al., 1992; Rey et al., 1994). Unlike LTP, CORT facilitates LTD via GR activation (Xu et al., 1997, 1998; Yang et al., 2005; Chaouloff et al., 2008).

\section{TIMING AND DURATION OF CORT APPLICATION}

Although CORT is better known for its suppressing effect on LTP, recent findings suggest that depending on the timing of LTP induction, CORT may also facilitate LTP. For instance, a brief application of stress level CORT $(100 \mathrm{nM})$ facilitates LTP if it is applied immediately before tetanus stimulation (Wiegert et al., 2006). This facilitating effect of CORT contrasts with its suppressing action on LTP when plasticity is induced hours later (Krugers et al., 2005; Wiegert et al., 2005). Note that membrane bound corticosteroid receptors (Wiegert et al., 2006) have been implicated in these facilitatory effects of CORT on memory. The rapid, acute facilitatory effect of CORT on LTP may relate to the positive impact of intrinsic stress (stress during learning) on the acquisition and consolidation of memory [for review, see (Sandi and Pinelo-Nava, 2007)].

While LTP is facilitated by acute CORT, prolonged CORT exposure suppresses LTP (Kerr et al., 1994). LTP is also suppressed in chronically stressed rats (Gerges et al., 2001; Pavlides et al., 2002; Alfarez et al., 2003) [but also see (Holderbach et al., 2007)]. In addition, LTD can be facilitated in animals exposed to chronic stress (Yang et al., 2006, 2007; Ma et al., 2007) or chronic CORT infusion (Dumas et al., 2010).

\section{SUBFIELD OF THE HIPPOCAMPUS}

Our understanding of the impact of CORT on synaptic plasticity is primarily informed by studies performed in the hippocampal CA1 region. CORT also affects synaptic plasticity in other hippocampal subfields. For instance, one hour after GR agonist application, LTP is suppressed in the dentate gyrus (DG) (Pavlides et al., 1995). Similar to the CA1 region, CORT induces rapid facilitation of LTP in the DG. Stressing rats with a brief forced swimming $15 \mathrm{~min}$ after LTP induction converts a short-lasting DG LTP into a long-lasting form (Korz and Frey, 2003) and this effect is mediated by MR activation. The impact of CORT on DG LTD is less clear. A typical LTP protocol induces LTD in GR agonist-treated DG slices (Pavlides et al., 1995), suggesting that LTD in the DG is also facilitated by CORT. Acute stress also suppresses mossy-fiber LTP in the CA3 region through a GR-mediated pathway (Chen et al., 2010). Whether CORT exerts a rapid-onset facilitatory effect on LTP in the CA3 region remains unclear.

\section{SUBREGIONS OF THE HIPPOCAMPUS}

The hippocampus can also be separated into dorsal (septal) and ventral (temporal) subregions. Not only do these hippocampal subregions receive distinct synaptic inputs from the entorhinal cortex (Dolorfo and Amaral, 1998), they also subserve different 
cognitive roles. Lesion of the dorsal hippocampus impairs spatial learning and memory (Moser et al., 1993). However, damage to the ventral hippocampus, which connects with the bed nucleus of the stria terminalis and the amygdala (Swanson and Cowan, 1977; Van and Wyss, 1990; Pitkanen et al., 2000), alters performance in fear- and anxiety-related behavioral tasks (Richmond et al., 1999; McHugh et al., 2004). While spatial learning can be suppressed by stress (Conrad et al., 1996; Diamond et al., 1996), stress typically enhances fear- and anxiety-related behaviors. One would, therefore, expect that stress differentially regulates encoding in these two hippocampal regions through opposing effects on synaptic plasticity. In agreement with this hypothesis, it has been shown that while CORT suppresses LTP in the dorsal hippocampus, this stress hormone facilitates LTP in the ventral hippocampus (Maggio and Segal, 2007). The effects of CORT on different hippocampal subregions are mediated by different corticosteroid receptors. MR activation facilitates LTP in the ventral hippocampus, whereas GR activation is responsible for suppressing LTP in the dorsal hippocampus. Notably, the form of LTP that is facilitated by CORT in the ventral hippocampus is not NMDAR dependent but requires activation of voltage-gated calcium channels. CORT also exerts opposing regulation of LTD in the dorsal and ventral hippocampi (Maggio and Segal, 2009). In the dorsal hippocampus, CORT activates GR to enhance LTD formation. However, LTD is suppressed by CORT in the ventral hippocampus through a MR-mediated mechanism.

\section{GENDER}

Our current understanding of the impact of CORT on synaptic plasticity is dominated by findings obtained from male rodents. Available evidence suggests that gender could affect the impact of CORT on synaptic plasticity. For instance, while chronic restraint stress impairs spatial memory in a radial arm maze in male rats, similar stress enhances performance in female rats in this task (Luine et al., 2007). Gender differences in Morris water maze performance are abolished by adrenalectomy (Beiko et al., 2004), suggesting that these differences are glucocorticoid dependent. Gender differences in stress responsiveness are also observed at the level of synaptic plasticity. For instance, the maintenance of DG LTP induced by stimulation of the lateral perforant path in male and female rats is sensitive to MR (Velisek et al., 2003) and GR blockade (Velisek and Vathy, 2005), respectively. In addition, while hippocampal LTD is facilitated in slices obtained from acutely stressed male rats, similar stress-induced facilitation of LTD cannot be observed in slices from stressed female rats (Huang et al.). Gender-dependent CORT effects on hippocampal function may also be regionally specific: while CORT inhibits neurogenesis in both the dorsal and ventral region of hippocampus in male rats, an inhibitory effect on neurogenesis is only observed in the ventral hippocampus of female rats (Brummelte and Galea, 2010).

\section{CORT REGULATION OF PRE- AND POST-SYNAPTIC FUNCTION}

CORT exerts biphasic effects on synaptic plasticity. These actions may relate to changes in glutamatergic transmission. Existing evidence suggests that the rapid effect of CORT is to enhance neuronal excitability and glutamate release, while the delayed effect is to normalize activity to pre-stimulation levels (Joels et al., 2007). CORT induces rapid alterations in both pre- and post-synaptic function. In vivo, CORT enhances extracellular glutamate levels within the hippocampus rapidly (within $15 \mathrm{~min}$ ) and transiently (return to baseline within 30-45 min) and these effects are insensitive to both GR and MR antagonists (Venero and Borrell, 1999). In vitro, CORT-induced increases in the frequency but not the amplitude of mEPSCs in CA1 pyramidal neurons and DG granule neurons after brief CORT treatment point to an effect on presynaptic glutamate transmission (Katz, 1971). This effect is reproduced by membrane impermeable BSA-CORT and the endogenous mineralocorticoid, aldosterone, and blocked by the MR-antagonist spironolactone (Karst et al., 2005; Pasricha et al., 2011) implicating a membrane-bound MR. Similarly, in CA1 pyramidal neurons in acute slices CORT rapidly reduces paired-pulse facilitation (Karst et al., 2005), a measure sensitive to alterations in presynaptic function (Debanne et al., 1996), providing a further demonstration that CORT increases presynaptic glutamate release. In parallel to effects on presynaptic function, CORT rapidly alters postsynaptic function, increasing neuronal excitability via inhibition of $I_{A}$ conductance of voltage-gated potassium channels. This inhibition is blocked by the MR-antagonist spironolactone or intracellular application of a G-protein inhibitor to the postsynaptic neuron (Karst et al., 2005; Olijslagers et al., 2008).

Following the rapid effects of CORT, the delayed, genomic effects of CORT may compensate for the increased glutamatergic transmission induced by rapid membrane-receptor mediated actions by suppressing neuronal excitability to restore $\mathrm{Ca}^{2+}$ homeostasis. Although increased $\mathrm{Ca}^{2+}$ influx is maintained by the upregulation of voltage-gated calcium currents (Karst et al., 2000), this enhances the slow after hyperpolarization, reducing neuronal excitability (Joels and de Kloet, 1989). However, recent evidence suggests that delayed upregulation of voltage-gated calcium currents does not occur in the DG highlighting the subfield specific nature of genomic CORT effects in the hippocampus (Van Gemert et al., 2009). Thus, the delayed effects of CORT may act to curtail a period of enhanced plasticity induced by acute stress and limit further changes in synaptic strength.

\section{CORT AND GLUTAMATE RECEPTORS}

Apart from regulating presynaptic release of glutamate and postsynaptic depolarization of neurons, increasing findings suggest that CORT directly alters the functional properties and plasticity of glutamate receptors. Notably, glutamate receptors, including the NMDAR and AMPAR subtypes, are critical mediators of the induction and maintenance of synaptic plasticity. Changes in NMDAR and AMPAR properties after CORT treatment would therefore significantly impact synaptic plasticity. Below we discuss the impact of CORT on these two ionotropic glutamate receptor species.

\section{GLUTAMATE RECEPTORS AND SYNAPTIC PLASTICITY}

NMDAR, AMPAR, and kainate receptors belong to the family of ionotropic glutamate receptors (Dingledine et al., 1999). They are multimeric assemblies of distinct subunits. NMDAR 
subunits include GluN1 (Moriyoshi et al., 1991), GluN2 [A-D (Kutsuwada et al., 1992; Meguro et al., 1992; Monyer et al., 1992; Ishii et al., 1993)], and GluN3 [A-B (Ciabarra et al., 1995; Sucher et al., 1995; Chatterton et al., 2002)]. Functional NMDARs contain GluN1 plus at least one type of GluN2 subunit (Seeburg, 1993; Dingledine et al., 1999). The most common GluN2 subunits in the adult hippocampus are GluN2A and GluN2B (Kirson and Yaari, 1996; Laurie et al., 1997; Wenzel et al., 1997). Four AMPAR subunits (GluA1-4) have been identified (Nakanishi, 1992; Hollmann and Heinemann, 1994; Dingledine et al., 1999). NMDAR plays pivotal roles in LTP (Collingridge et al., 1983) and LTD formation (Dudek and Bear, 1992) because: (1) it is highly conductive to $\mathrm{Ca}^{2+}$ (MacDermott et al., 1986), a crucial chemical signal for synaptic plasticity (Bliss and Collingridge, 1993; Bear and Abraham, 1996); (2) its opening is gated by a voltage-sensitive $\mathrm{Mg}^{2+}$ blockade that is removed by depolarization (Nowak et al., 1984). The latter property allows NMDAR to serve as a coincidence detector of simultaneous presynaptic glutamate release and postsynaptic depolarization, which is fundamental to induction of synaptic plasticity. The presence of $\mathrm{Mg}^{2+}$ blockade also limits the contribution of NMDAR to basal synaptic transmission. Thus, long-term alteration of the strength of glutamate synapses after LTP and LTD induction is expressed by changes in the gating (Benke et al., 1998) and/or trafficking (Malenka, 2003; Collingridge et al., 2004) properties of AMPAR in glutamate synapses.

\section{CORT AND THE PLASTICITY OF AMPAR}

CORT facilitates AMPAR-mediated synaptic transmission by increasing the frequency of AMPAR-mediated miniature excitatory postsynaptic currents [EPSC, (Karst and Joels, 2005)]. In addition, CORT enhances the mobility of AMPAR by facilitating exo/endocytotic exchange between cytosolic and surface receptors (Martin et al., 2009) and lateral trafficking between synaptic and extra-synaptic receptors (Groc et al., 2008). The effect of this increased mobility is likely an enrichment of GluA2 subunits in glutamate synapses (Martin et al., 2009). While these changes in AMPAR function could explain the facilitating effect of CORT on synaptic plasticity, they take hours to develop (Karst et al., 2005; Martin et al., 2009). Thus, these slow-onset changes likely contribute little to rapid CORT-induced alterations of LTP (Wiegert et al., 2006) and LTD (within minutes) (Xu et al., 1997). Moreover, how facilitation of AMPAR function contributes to the delayed suppressive effect of CORT on synaptic plasticity remains unclear.

\section{PLASTICITY OF NMDARS IN THE ADULT HIPPOCAMPUS}

Until recently, NMDAR in the adult brain was believed to be highly stable. Electron microscopy studies reveal that the number of immunogold labeled NMDARs per hippocampal synapse from P10 rats is almost identical to that from 5-week-old rats (Petralia et al., 1999). In marked contrast, the number of labeled AMPARs increases 2-3-fold during the same developmental period. The potential for plasticity of NMDAR (i.e., alteration of the expression and/or electrophysiological properties of NMDAR channels) is also reduced across the course of brain development. For instance, plastic changes in NMDAR subunit composition are triggered by high frequency stimulation in developing hippocampal tissue $(<\mathrm{P} 10)$ but cannot be induced in tissue from 3-week-old rats (Bellone and Nicoll, 2007). In addition, stimulation protocols that induce LTP of AMPAR-mediated synaptic currents do not robustly alter NMDAR-mediated synaptic currents (Muller et al., 1988; Perkel and Nicoll, 1993) [but also see (Bashir et al., 1991; Grosshans et al., 2002)]. The increasing resistance of NMDAR-mediated synaptic currents to plastic alteration across development is likely related to the dramatic alterations of NMDAR subunit composition. In particular, in the first postnatal month there is a switch from GluN2B-enriched to GluN2A-enriched NMDAR in glutamate synapses (Sheng et al., 1994; Ritter et al., 2002). GluN2A-containing NMDARs display less horizontal [between synaptic and extra-synaptic locations (Groc et al., 2006)] and vertical motility [between surface membrane and cytosol (Barria and Malinow, 2002)] than GluN2Bcontaining receptors. Although GluN2B-containing NMDARs can still be found in adult glutamate synapses (Erisir and Harris, 2003), the developmental increase in GluN2A subunits could greatly enhance NMDAR stability. Taken together, these findings suggest that a high stability of NMDAR function is actively maintained in adult glutamate synapses. Despite this, recent findings have challenged the long-held assumption that plasticity of NMDAR function is difficult to induce in the adult brain.

Several lines of evidence suggest that plastic changes of NMDAR are induced in an experience dependent manner in the adult brain. Dopamine alters NMDAR-mediated synaptic currents in the adult brain (Varela et al., 2009). Apart from changing the size of NMDAR-mediated currents, NMDAR subunit composition is also subject to plasticity in the adult brain. For instance, the ratio of GluN2A/GluN2B mRNA expression varies with the reproductive cycle of female rats (Gore et al., 2000), seasonal testosterone levels of male song birds (Singh et al., 2003), and chronic stress exposure (Qin et al., 2004). Although the functional consequences of these subunit modifications remain unknown, these findings raise two important points. Firstly, steroidal hormones, including CORT, could be potent biological modulators of NMDAR function in the adult brain. Secondly, even after the developmental switch of NMDAR from GluN2B-enriched to a GluN2A-enriched, the potential remains for further GluN2 subunit change in response to stressful experiences. The effect of CORT on NMDAR function is supported by findings obtained in young (acute slices prepared from early postnatal brains) and developing brain tissue (cultured neurons prepared from embryonic brains). CORT can both facilitate (Takahashi et al., 2002) and attenuate (Sato et al., 2004; Liu et al., 2007) NMDARmediated $\mathrm{Ca}^{2+}$ influx and current in both cultured neurons and young hippocampal slices. How CORT mediates bidirectional changes in the electrophysiological properties of NMDAR remains unclear. Notably, whether NMDAR function in the adult brain remains sensitive to modulation by CORT is yet to be widely investigated.

\section{CORT-INDUCED ENHANCEMENT OF NMDAR FUNCTION IN THE ADULT HIPPOCAMPUS}

Recently, we addressed the issue of the capacity of CORT to induce changes in synaptic NMDAR function in the adult brain 
using an adult (3-month old) rat hippocampal slice preparation (Tse et al., 2011). The findings of these studies identified both a fast-onset and long-lasting increase in synaptic NMDAR function following a $30 \mathrm{~min}$ exposure to stress level (100 nM) CORT. Note that $100 \mathrm{nM}$ CORT approximates CORT levels measured by microdialysis in vivo in rat hippocampus shortly after exposure to an intense stressor such as forced swimming (Droste et al., 2009). A single $30 \mathrm{~min}$ CORT application increased NMDAR function at glutamate synapses in the dorsal hippocampal CA1 region as reflected by an increase in normalized NMDAR-mediated field excitatory postsynaptic potentials (NMDAR-fEPSPs). Surprisingly, using a similar methodology we did not observe an effect of CORT on AMPAR function measured by normalized AMPAR-fEPSPs. Importantly, there was a parallel increase in the ratio of evoked NMDAR-mediated EPSCs (NMDAR-EPSCs) vs. AMPAR-EPSC after CORT treatment using whole-cell patch clamp recording. This further confirms that CORT enhances NMDAR function. Moreover, although CORT treatment was limited to $30 \mathrm{~min}$, we found that the rapid CORTinduced increase in NMDAR/AMPAR ratio lasted for at least two hours after wash-out of CORT. It is important to consider the specific temporal parameters used when interpreting the lack of AMPAR changes in this study. Since CORT-induced alterations in AMPAR expression and function were previously observed 2-3 h post-treatment (Karst and Joels, 2005; Groc et al., 2008; Martin et al., 2009), the time window in which we observed alterations in NMDAR function may precede these slow-onset changes.

As reviewed above, NMDAR function is critically implicated in synaptic plasticity and CORT exerts a complex regulation of bidirectional synaptic plasticity. Thus, we asked how the acute modulation of NMDAR function by CORT might manifest in regulation of bidirectional synaptic plasticity. We found that during CORT treatment, both LTP and LTD of AMPAR fEPSPs were facilitated relative to vehicle treated slices. This finding is consistent with the fast-onset facilitation of bidirectional synaptic plasticity by stress (Xu et al., 1997) and CORT (Xu et al., 1998; Wiegert et al., 2006). This phenomenon might be attributable to enhanced NMDAR function in the presence of CORT. This would increase calcium influx during LTP and LTD induction and increase the magnitude of plastic change. However, the completeness of this explanation is challenged by our finding that synaptic plasticity was not facilitated $1-2 \mathrm{~h}$ after a brief CORT treatment despite sustained enhancement of NMDAR function. To resolve the question of why CORT no longer facilitated synaptic plasticity although synaptic NMDAR function remained enhanced, a more thorough characterization of CORT effects on NMDAR was required.

\section{CORT-INDUCED ALTERATION OF NMDAR SUBUNIT COMPOSITION IN THE ADULT HIPPOCAMPUS}

Apart from modulating the synaptic currents mediated by NMDAR, CORT might also regulate the GluN2 subunit composition of NMDAR to modulate induction of bidirectional synaptic plasticity. In the hippocampus, GluN2A and GluN2B are the two most common GluN2 subunits. Expression of GluN2 subunits is developmentally regulated. In early postnatal stages (e.g., $<1$ month), hippocampal NMDARs are mostly GluN2B-containing
(Monyer et al., 1994). GluN2A expression increases with development and predominates in the adult hippocampus (Wenzel et al., 1997). GluN2 subunits play important roles in determining NMDAR function (Monyer et al., 1994). For example, blocking GluN2B-containing NMDAR using Ro25-6981 inhibits LTD formation in vitro and in vivo, whereas blocking GluN2Acontaining NMDAR selectively abolishes LTP (Liu et al., 2004; Ge et al., 2010). Nonetheless, how different GluN2 subunits contribute to bidirectional synaptic plasticity is still extensively debated [for review, see (Yashiro and Philpot, 2008; Fetterolf and Foster, 2011)]. Differences in biophysical properties and signaling between GluN2A and GluN2B may be responsible for their differential roles in synaptic plasticity.

GluN2A-containing NMDAR displays larger conductance and faster decay kinetics than GluN2B-containing NMDAR (Monyer et al., 1994). Findings from single channel studies also reveal higher opening probability and faster conformational changes in GluN2A-containing NMDAR compared with GluN2B-containing NMDAR (Erreger et al., 2005). Due to their more rapid conformational change, GluN2A-containing NMDARs may contribute more to calcium transfer than GluN2Bcontaining NMDARs during LTP-inducing high frequency stimulation. In contrast, LTD-inducing low frequency stimulation protocols would favor charge transfer through GluN2Bcontaining NMDAR. Alternatively, the carboxyl terminal of GluN2 subunit, which interacts with different scaffolding or signaling proteins, could determine the polarity of synaptic plasticity. For instance, mice expressing GluN2A subunit without the carboxyl terminal are deficient in hippocampal LTP formation (Kohr et al., 2003). This finding suggests that the carboxyl terminal of GluN2A may recruit signaling proteins that are responsible for LTP formation. However, the contribution of GluN2A to LTP may follow an inverted U-shape relationship. Overexpression of GluN2A subunit in cultured hippocampal slices impairs LTP (Foster et al., 2010). Overexpressing carboxyl-terminal truncated GluN2A subunit does not affect LTP formation, suggesting that excessive GluN2A impairs LTP through recruiting LTP-blocking signaling proteins that bind the carboxyl terminal of GluN2A subunit. The identity of proteins that bind to the carboxyl terminal of GluN2A subunit to facilitate or suppress LTP formation remain unknown. Although knocking down GluN2B abolishes LTD formation (Brigman et al., 2010), little is known about the contribution of GluN2B carboxyl terminal to LTD formation.

When we assessed glutamate receptor surface membrane expression the data strongly suggested that CORT increased the ratio of GluN2A/GluN2B. CORT increased the surface GluN2A and GluN1 expression measured in hippocampal synaptosomes yet did not affect the expression of GluN2B or GluA1, an AMPAR subunit. GluN2A and GluN1 expression was not increased during CORT treatment but only $1-2 \mathrm{~h}$ after the cessation of CORT treatment. Interestingly, the time-course of increased GluN2A corresponds to the time-course of the attenuation of CORT-induced facilitation of bidirectional synaptic plasticity. An increase in GluN2A could inhibit both LTP and LTD formation. Increased GluN2A/GluN2B ratio lowers the synaptic contribution of GluN2B-containing NMDAR. This could reduce LTD which requires GluN2B-NMDAR activation (Liu et al., 2004; 
Ge et al., 2010). As mentioned earlier, excess GluN2A expression inhibits LTP formation (Foster et al., 2010). Increased synaptic expression of GluN2A subunit could be one mechanism through which rapid facilitation of synaptic plasticity is attenuated in the period hours after CORT or stress exposure.

Since GluN2 subunits undergo substantial developmental changes, CORT-induced changes in NMDAR subunit composition may differ with developmental stage. In one-month-old rats that exhibit high GluN2B expression, acute stress increases synaptic NMDAR function in the prefrontal cortex (PFC) (Yuen et al., 2009). In contrast to the selective increase of GluN2A expression in CORT-treated adult hippocampus, both GluN2A and GluN2B expression are enhanced by stress in juvenile PFC synapses. However, these findings could also suggest a regional difference in the regulation of NMDAR expression by CORT between the PFC and the hippocampus. Future studies, are necessary to determine the impact of CORT on NMDAR subunit composition in young hippocampal tissue.

Our findings suggest that NMDAR in the adult hippocampus is altered by brief exposure to stress level CORT (Figure 1). The enhancement of NMDAR occurs rapidly during CORT treatment. This rapid enhancement associates with facilitation of bidirectional synaptic plasticity. However, increased NMDAR function is followed by increased synaptic expression of GluN1 and GluN2A subunits. This secondary effect associates with the loss of synaptic plasticity facilitation. We suggest that plastic alteration of synaptic NMDAR in the adult hippocampus is instrumental to CORT regulation of synaptic plasticity. Regulation of synaptic plasticity by CORT in adulthood is programmed by early life experience.

\section{Before CORT}

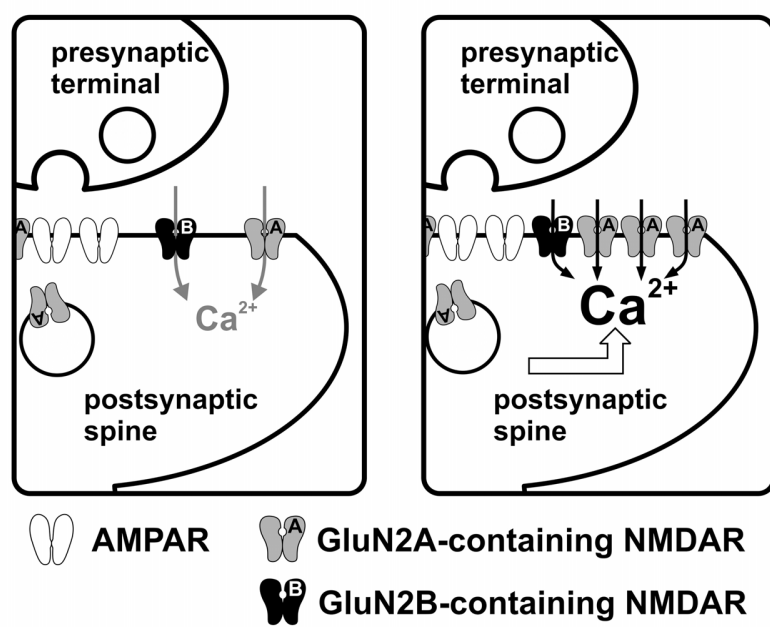

FIGURE 1 | CORT-induced dynamic regulation of synaptic NMDARs in the adult hippocampus. Schematic diagrams summarize the impact of CORT on NMDAR function. Compared with controls (/eft), stress level CORT treatment $(100 \mathrm{nM}, 30 \mathrm{~min})$ induces a fast-onset increase in synaptic NMDAR function and a slow-onset (1-2 h after CORT treatment) enhancement of the surface expression of GluN2A-containing NMDAR (right).
As we will discuss below, maternal care exerts a lasting impact on stress effects on hippocampal synaptic plasticity.

\section{HIPPOCAMPAL COGNITIVE DEVELOPMENT AND MATERNAL CARE}

The early environment exerts profound and enduring effects on hippocampal development and function (Bornstein and TamisLeMonda, 1989; Liu et al., 2000; Champagne et al., 2008). In rodents, the tactile stimulation provided by maternal pupdirected licking/grooming (LG) is an important component of the early environment (Schanberg et al., 1984). Intensive characterization of naturally occurring variations in maternal behavior in outbred Long-Evans rats reveals that the frequency of LG is normally distributed within the population and the relative frequency with which a rat dam licks and grooms her pups is stably maintained across subsequent litters (Champagne et al., 2003). The frequency of LG behavior can be used to identify two populations of rats in which to examine the consequences for offspring development of comparatively low (Low LG) and high (High LG) levels of maternal stimulation.

Maternal LG frequency is positively correlated with hippocampus-dependent learning in adult male offspring. Compared to Low LG offspring, offspring of High LG mothers learn the location of a hidden platform in the Morris water maze in fewer trials and exhibit enhanced recall of the platform location in probe tests (Liu et al., 2000). The offspring of High LG mothers also show enhanced memory in an object recognition task (Bredy et al., 2003). Consistent with enhanced hippocampaldependent learning and memory, the magnitude of LTP in the hippocampal DG of High LG offspring is greater than in Low LG offspring (Bredy et al., 2003; Champagne et al., 2008; Bagot et al., 2009). Maternal effects on hippocampal synaptic plasticity and memory associate with increases in hippocampal NMDAR and AMPAR mRNA subunit expression and receptor binding as well as enhanced cholinergic innervation of the hippocampus (Liu et al., 2000; Bredy et al., 2003, 2004). Furthermore, hippocampal morphology is influenced by maternal care and dendritic arborization and spine density is also increased in the hippocampal CA1 of High LG offspring (Champagne et al., 2008; Bagot et al., 2009).

\section{MATERNAL CARE AND STRESS RESPONSIVITY}

In addition to effects on cognitive development, maternal care influences stress reactivity and the hypothalamic-pituitaryadrenal (HPA) stress axis. High levels of pup LG in early life are associated with reduced stress responsivity in adulthood. Compared to the adult offspring of Low LG mothers, those of High LG dams show lower plasma levels of adrenocorticotropic hormone (ACTH) and CORT both during and following the termination of acute restraint stress (Liu et al., 1997). Upregulation of GR expression in all hippocampal subfields is an important mediator of the enhanced negative feedback control in adult animals exposed to high levels of maternal LG (Liu et al., 1997; Francis et al., 1999; Weaver et al., 2004). During stress-induced elevations in CORT, GRs become progressively occupied and thus hippocampal control of stress-induced HPAaxis activity is mediated by stimulation of GR activity by CORT 
(de Kloet et al., 1998; Furay et al., 2008). Manipulations that increase hippocampal GR expression, such as early-life handling are associated with attenuated post-stress plasma ACTH and CORT levels (Meaney et al., 1985; Viau et al., 1993). Reductions in GR expression, such as occur in aged animals, are associated with prolonged increases in stress-induced plasma CORT (Morano et al., 1994). The central role of the hippocampus as target and regulator of the HPA-axis suggests that alterations of HPA-axis activity should have wide ranging consequences for hippocampal learning and plasticity. Indeed, brief CORT treatment suppresses LTP formation in the dorsal hippocampal CA1 (Champagne et al., 2008) and DG (Bagot et al., 2009) of High LG offspring. However, LTP is facilitated by CORT in Low LG offspring. Stress also enhances hippocampus-dependent learning in Low LG offspring in contextual fear-conditioning (Bagot et al., 2009). Thus the maternal effect on stress responsivity influences hippocampus-dependent learning and synaptic plasticity. Given the fundamental roles of NMDAR in synaptic plasticity, maternal care might regulate hippocampal function through actions on this glutamate receptor. Findings from expression and binding studies suggest LG experience enhances the expression of NMDAR subunits GluN1, GluN2A, and GluN2B in the hippocampus (Liu et al., 2000). Nonetheless, changes in NMDAR expression and binding do not directly reflect the functional properties of NMDAR activation in synapses, which is crucial to synaptic plasticity.

\section{NMDAR SYNAPTIC FUNCTION IS INCREASED IN LOW LG OFFSPRING}

In contrast to earlier studies of receptor expression, recent work in our laboratory employing functional measures of glutamate receptor activity suggest that NMDAR function is enhanced in Low LG offspring (Bagot et al.). In the dorsal DG, normalized NMDAR-fEPSPs are significantly larger in Low LG than High LG offspring. However, AMPAR-fEPSPs do not differ between High and Low LG offspring indicating the maternal effect is specific to NMDAR function. Whole-cell recording experiments further support this conclusion. The ratio of the amplitude of NMDAR-EPSCs vs. the amplitude of AMPAR-EPSCs is significantly increased in Low LG offspring. Given that Low LG offspring also exhibit deficits in LTP (Bredy et al., 2003; Champagne et al., 2008; Bagot et al., 2009) this increase in NMDAR function is surprising. Enhanced NMDAR function could be expected to reduce the threshold and enhance the magnitude of LTP. However, over-activation of NMDAR induced by low extracellular $\mathrm{Mg}^{2+}$ conditions during LTP induction (Coan et al., 1989; Frankiewicz and Parsons, 1999) or excessive cleft glutamate (Katagiri et al., 2001) impairs LTP. Thus, excessive NMDAR activation during LTP induction might underlie the loss of LTP in offspring of Low LG mothers.

\section{MATERNAL CARE ALTERS CORT-REGULATION OF NMDAR FUNCTION}

Although maternal care might be expected to differentially affect CORT-regulation of NMDAR function, the direction of such an effect is difficult to predict based on previous findings. Since High LG offspring are less stress responsive than Low LG offspring, one might expect CORT to exert a stronger impact on NMDAR in Low LG offspring. Alternatively, since High LG offspring express higher levels of GR in the hippocampus, and GR activation is necessary for CORT-induced enhancement of NMDAR function (Tse et al., 2011), CORT may more potently regulate NMDAR function in High LG offspring. In fact, we found that stresslevel CORT (100 nM) significantly enhanced NMDAR function in High LG offspring and increased the normalized NMDARfEPSP. In contrast, CORT treatment had no detectable effect on NMDAR-fEPSPs in Low LG offspring. The mechanism underlying the loss of CORT-regulation of NMDAR in Low LG offspring is unclear. Since NMDAR function is maintained at a high and possibly saturated level in Low LG offspring in basal conditions, the capacity for further enhancement of NMDAR function after CORT treatment could be limited. Interestingly, the time-course of CORT-induced enhancement of NMDAR function (within $20 \mathrm{~min}$ ) suggested that a classical genomic action requiring cytoplasmic corticosteroid receptors is not involved. Indeed the CORT effect was reproduced by a BSA-CORT conjugate, implicating the involvement of a membrane-bound corticosteroid receptor. Thus, similar to the non-genomic effects of CORT in facilitating AMPAR (Karst et al., 2005) and LTP formation (Wiegert et al., 2006), CORT-induced facilitation of synaptic NMDAR in the adult hippocampus of High LG offspring is likely mediated by non-genomic mechanisms.

Almost all NMDARs in the adult hippocampus are GluN2Aand GluN2B-containing, and these two subunits exhibit fast and slow decay properties (Monyer et al., 1994). Our findings suggest that GluN2A expression in the hippocampal synapses of Low LG offspring may be higher than High LG offspring although this requires further investigation. After CORT treatment the decay time constant of NMDAR current is significantly reduced only in High LG offspring. Thus, the decay properties of NMDAR current in Low LG offspring are unresponsive to CORT treatment, similar to the lack of effect of CORT on synaptic NMDAR currents. Insertion of fast-decaying GluN2A subunit may occur in the hippocampal synapses of High LG offspring after CORT treatment although this has not been examined.

\section{POSSIBLE MECHANISMS OF CORT-INDUCED CHANGES IN NMDAR IN THE ADULT BRAIN}

Stress level CORT induces a rapid (within $30 \mathrm{~min}$ ) long-lasting enhancement and faster decay kinetics of synaptic NMDAR function in hippocampal synapses of High LG offspring. This rapid effect of CORT is mediated by membrane-bound corticosteroid receptors (Figure 2). Although rapid enhancement of NMDAR-mediated $\mathrm{Ca}^{2+}$ influx by CORT has been reported (Takahashi et al., 2002; Xiao et al., 2010), the mechanism is unclear. Evidence of very rapid effects of CORT [seconds to minutes (Dallman and Yates, 1969)] inconsistent with the temporal requirements for transcription and translation has long suggested the existence of non-genomic actions of CORT. The existence of a putative membrane-receptor is supported by membrane-localized GR-antibody staining in rat hippocampal, hypothalamic, and amygdala neurons (Liposits and Bohn, 1993; Johnson et al., 2005). Additionally, membrane-impermeable BSA-CORT efficiently reproduces certain CORT effects on neuronal excitability, memory consolidation, and neurotoxicity (Takahashi et al., 2002; Karst et al., 2005; Roozendaal et al., 


\section{Before CORT}

After CORT

\section{High LG offspring}
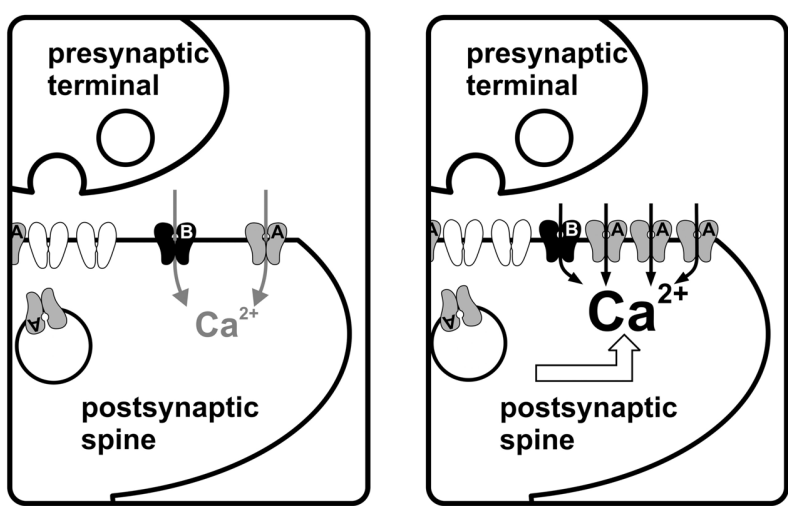

AMPAR

$S^{A}$ GluN2A-containing NMDAR

GluN2B-containing NMDAR

\section{Before CORT}

After CORT

\section{Low LG offspring}

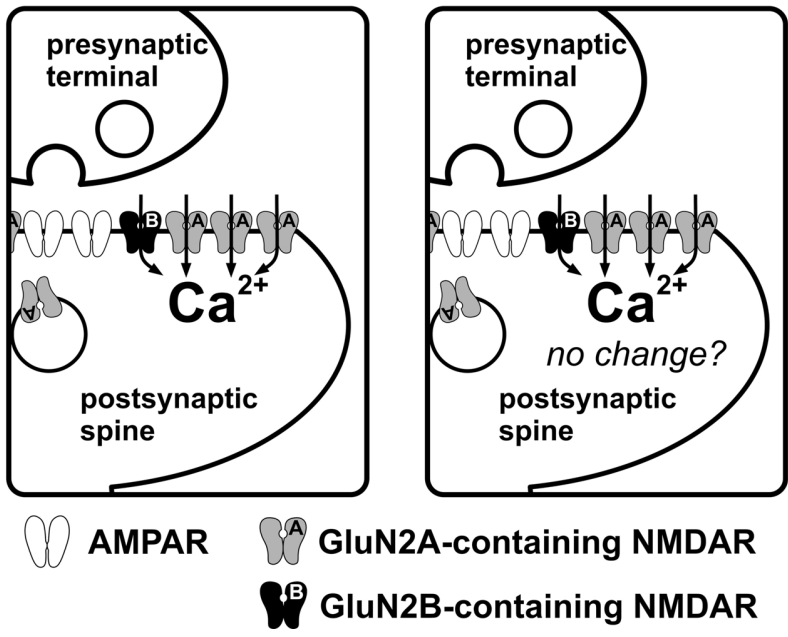

FIGURE 2 | Effects of maternal care on CORT-induced regulation of synaptic NMDARs in the adult hippocampus. Schematic diagrams summarize the impact of CORT on NMDAR function and synaptic plasticity. In High LG offspring, stress level CORT (100 nM, $30 \mathrm{~min}$ ) induces a fast-onset increase in synaptic NMDAR current and a reduction of NMDAR decay kinetics, which may result from an increase in synaptic GluN2A expression. The same CORT treatment produces no observable alteration of NMDAR function or decay kinetics in Low LG offspring. Potential alteration of other ionotropic receptors species (e.g., lateral trafficking of AMPAR) after CORT treatment in Low LG offspring has not been investigated.
2010; Xiao et al., 2010). However, the identity of a putative membrane-corticosteroid receptor is debated (Riedemann et al., 2010; Groeneweg et al., 2011) and as such, discussion of the mechanism by which CORT rapidly enhances NMDAR function is speculative. A rapid, specific potentiation of NMDAR current could be mediated by alterations in the properties of existing synaptic NMDARs or by addition of receptors to the postsynaptic density. Although less mobile than AMPARs, the population of synaptic NMDARs is dynamically regulated by processes of lateral diffusion and receptor insertion (Tovar and Westbrook, 2002). Whether such a process is rapidly modulated by CORT is unknown. However, it is interesting to note that PKC enhances lateral diffusion of NMDARs (Groc et al., 2004) and PKC activation by CORT is implicated in the signal transduction mechanisms of putative membranecorticosteroid receptors in hippocampal neuronal cultures (Qi et al., 2005).

Findings obtained from non-hippocampal regions may also shed light on mechanisms underlying CORT-induced regulation of NMDAR (Yuen et al., 2009, 2011). Acute stress increases synaptic NMDAR and AMPAR function in the PFC of young rats (one-month old) by enhancing synaptic expression of these receptors. This stress effect is blocked by a GR antagonist, suggesting involvement of CORT. In addition, the impact of CORT on NMDAR trafficking requires activation of serum- and glucocorticoid-inducible kinase and Rab4, which regulates receptor trafficking. Further studies are needed to reveal the involvement of these signaling pathways in CORT-induced regulation of NMDAR in the adult hippocampus.

\section{FUNCTIONAL IMPLICATIONS OF CORT-INDUCED INCREASE IN NMDAR IN THE ADULT BRAIN}

CORT-induced enhancement of NMDAR facilitates both LTP and LTD formation. These facilitating effects of CORT on synaptic plasticity could aid survival in threatening environments by fulfilling increased cognitive demands and supporting encoding of threat-relevant information that may enhance recognition of future threats. Critically, the facilitating effect of CORT on synaptic plasticity is short lasting, returning to basal conditions within one hour of the end of CORT exposure. Prolonged facilitation of hippocampal plasticity could enhance encoding of non-pertinent information, interfering with new memory traces formed during stress. Curtailing synaptic plasticity facilitation after CORT may be essential for appropriate encoding and storage of information relevant to the context in which stress is experienced. The delayed curtailment of the facilitation of synaptic plasticity after CORT could have a homeostatic role, resetting the threshold for synaptic plasticity to ensure the continued capacity for information storage in the hippocampus. The slow-onset increase in synaptic GluN2A expression may be one mechanism of such homeostatic regulation.

\section{INFLUENCE OF HIPPOCAMPAL SUBFIELD, SUBREGION, AND GENDER ON CORT-INDUCED ALTERATION OF NMDAR}

Our findings obtained from the dorsal CA1 and DG of adult rats reveal comparable enhancement of NMDAR function by 
CORT in both hippocampal subfields. These findings parallel the similar impact of acute stress and CORT on LTP in CA1 and DG (see section "Subfield of the Hippocampus"), suggesting that plastic changes of NMDAR are relevant to the regulation of synaptic plasticity in CA1 and DG. Whether CORT exerts similar enhancement of NMDAR function in CA3 is not known. Although the expression of GR, which is responsible for CORTinduced changes in NMDAR function (Yuen et al., 2009; Tse et al., 2011), in CA3 is reduced relative to CA1 and DG (Van Eekelen et al., 1988), CA3 neurons show profound reductions in dendritic arborization after chronic CORT or stress exposure (Woolley et al., 1990; Watanabe et al., 1992). CORT may also enhance NMDAR function in CA3. Recent findings suggest that metaplastic increases in NMDAR function caused by high frequency stimulation in the CA3 region support formation of NMDARdependent LTP in this hippocampal subfield (Rebola et al., 2011). Future experiments should investigate if CORT or acute stress also enhances NMDAR function in the CA3 region to regulate metaplasticity.

How factors such as hippocampal subregion and gender (see sections "Subregions of the Hippocampus" and "Gender") influence the CORT effects on NMDAR function has not been investigated. Dorsal and ventral hippocampus exhibit differential NMDAR expression. Both mRNA and protein expression of GluN2A and GluN2B in the dorsal hippocampus is increased relative to the ventral hippocampus (Pandis et al., 2006; Liu et al., 2008). Moreover, NMDAR function is likely not uniform along the dorsal-ventral axis of the hippocampus. For instance, NMDAR-dependent high frequency oscillations are more frequent in ventral hippocampus than in the dorsal hippocampus (Papatheodoropoulos, 2007). Hippocampal NMDAR subunit expression displays gender-specific differences (Palomero-Gallagher et al., 2003) and mRNA expression of GluN1 and GluN2A is also regulated by estrogen in female rats (Adams et al., 2001). Corticosteroid receptor expression also displays regional- and gender-specific differences. For instance, MR but not GR mRNA expression in the ventral hippocampus is higher than that in the dorsal hippocampus (Robertson et al., 2005). Although similar mRNA expression of MR and GR was found between the hippocampus of male and female rats, stress-induced changes in the expression of these receptors are greatly influenced by gender (Kitraki et al., 2004). Taken together these findings suggest that regional and gender differences could influence CORT-induced regulation of NMDAR function.

\section{CHRONIC STRESS AND CORT-INDUCED ALTERATION OF NMDAR IN THE ADULT BRAIN}

CORT-induced changes in NMDAR could have pathological consequences. Sustained, excessive activation of NMDAR leads to excitotoxicity (Choi, 1988), especially in the CA1 region (Ikegaya and Matsuki, 2002). Chronic stress is associated with atrophy of dendritic arbors of CA3 neurons (McEwen, 1999; Sapolsky, 2000). Along the longitudinal axis of CA3, chronic stress produces more extensive atrophy in the ventral (reduction in dendritic length and branches) than in the dorsal hippocampus (reduction in dendritic length only) (Christian et al., 2011). Stress-related hippocampal atrophy is ameliorated by pharmacological blockade of NMDAR function (Magarinos and McEwen, 1995) and genetic ablation of GluN1 in the CA3 region (Christian et al., 2011). However, AMPAR blockade is ineffective. We suggest that exposure to high levels of glucocorticoids during stress may render the hippocampus vulnerable to NMDAR-induced excitotoxicity. This increased vulnerability to excitotoxicity may arise from NMDAR hyperfunction in the chronically stressed hippocampus. For instance, three weeks of daily restraint stress increased synaptic NMDAR, but not AMPAR, currents in CA3 pyramidal neurons (Kole et al., 2002). Chronic stress also affects GluN2 subunit expression by decreasing GluN2B expression (Cui et al., 2009). In parallel with this finding, we have observed significant increases in synaptic expression of GluN2A subunit after brief CORT exposure (Figure 1). Taken together, these findings suggest that an increase in GluN2A/GluN2B ratio could be a neurobiological signature of chronic stress. It is interesting to note that increased GluN2A is implicated in the formation of depression-related behaviors in rodents (Taniguchi et al., 2009). Conversely, depression-related behavior is reduced in transgenic mice lacking the GluN2A subunit (Boyce-Rustay and Holmes, 2006).

\section{NMDAR HYPERFUNCTION AND DEPRESSION}

The World Health Organization estimates that by 2015 mood disorders, such as depression, will be the leading cause of health burden in the world. However, the clinical efficacy of pharmacological interventions has improved only modestly since the introduction of tricyclics in the late 1970's. Thus, recent findings of the fast acting antidepressant effect of the NMDAR antagonist ketamine have drawn a lot of attention (Pittenger et al., 2007; Skolnick et al., 2009). The antidepressant effects of ketamine are linked to the activation of BDNF (MachadoVieira et al., 2009) [but also see (Lindholm et al., 2012)] and mTOR pathways (Li et al., 2010). These antidepressant effects also suggest a state of NMDAR hyperfunction in the brain of depression patients. Findings obtained from Low LG offspring also point to a link between hippocampal NMDAR hyperfunction and depression. Low LG offspring have high levels of basal NMDAR function and exhibit depression-like behaviors in forced swimming and novelty suppression of feeding tests (Caldji et al., 1998; Weaver et al., 2005). Potentially, risk factors for depressive disorders, including early life adversity and chronic stress, could induce depression-related behavior by enhancing NMDAR function in the hippocampus. Future studies should validate this hypothesis by examining the antidepressant effect of NMDAR antagonists in Low LG offspring. Further understanding of the mechanisms underlying CORT-induced increases in NMDAR function could identify molecular targets to ameliorate NMDAR changes caused by chronic stress. Associated pharmacological advances may lead to novel therapeutic tools to treat depression and other stress-related mood disorders that are highly resistant to current therapies (Meltzer and McGurk, 1999; Butters et al., 2000). 


\section{REFERENCES}

Adams, M. M., Morrison, J. H., and Gore, A. C. (2001). N-methyl-Daspartate receptor mRNA levels change during reproductive senescence in the hippocampus of female rats. Exp. Neurol. 170, 171-179.

Alfarez, D. N., Joels, M., and Krugers, H. J. (2003). Chronic unpredictable stress impairs long-term potentiation in rat hippocampal CA1 area and dentate gyrus in vitro. Eur. J. Neurosci. 17, 1928-1934.

Atkinson, H. C., Wood, S. A., Kershaw, Y. M., Bate, E., and Lightman, S. L. (2006). Diurnal variation in the responsiveness of the hypothalamicpituitary-adrenal axis of the male rat to noise stress. J. Neuroendocrinol. 18, 526-533.

Avital, A., Segal, M., and RichterLevin, G. (2006). Contrasting roles of corticosteroid receptors in hippocampal plasticity. J. Neurosci. 26, 9130-9134.

Bagot, R. C., Tse, Y. C., Nguyen, H. B., Wong, A. S., Meaney, M. J., and Wong, T. P. Maternal care influences hippocampal NMDA receptor function and dynamic regulation by corticosterone in adulthood. (submitted).

Bagot, R. C., van Hasselt, F. N., Champagne, D. L., Meaney, M. J., Krugers, H. J., and Joels, M. (2009). Maternal care determines rapid effects of stress mediators on synaptic plasticity in adult rat hippocampal dentate gyrus. Neurobiol. Learn. Mem. 92, 292-300.

Barria, A., and Malinow, R. (2002). Subunit-specific NMDA receptor trafficking to synapses. Neuron 35, 345-353.

Bashir, Z. I., Alford, S., Davies, S. N., Randall, A. D., and Collingridge, G. L. (1991). Long-term potentiation of NMDA receptor-mediated synaptic transmission in the hippocampus. Nature 349, 156-158.

Bear, M. F., and Abraham, W. C. (1996). Long-term depression in hippocampus. Annu. Rev. Neurosci. 19, 437-462.

Beiko, J., Lander, R., Hampson, E., Boon, F., and Cain, D. P. (2004). Contribution of sex differences in the acute stress response to sex differences in water maze performance in the rat. Behav. Brain Res. 151, 239-253.

Bellone, C., and Nicoll, R. A. (2007). Rapid bidirectional switching of synaptic NMDA receptors. Neuron 55, 779-785.

Benke, T. A., Luthi, A., Isaac, J. T., and Collingridge, G. L. (1998). Modulation of AMPA receptor unitary conductance by synaptic activity. Nature 393, 793-797.

Bliss, T. V., and Collingridge, G. L. (1993). A synaptic model of memory: long-term potentiation in the hippocampus. Nature 361, 31-39.

Bliss, T. V., and Lomo, T. (1973). Long-lasting potentiation of synaptic transmission in the dentate area of the anaesthetized rabbit following stimulation of the perforant path. J. Physiol. 232, 331-356.

Bornstein, M. H., and Tamis-LeMonda, C. S. (1989). Maternal responsiveness and cognitive development in children. New Dir. Child Dev. 43, 49-61.

Boyce-Rustay, J. M., and Holmes, A. (2006). Genetic inactivation of the NMDA receptor NR2A subunit has anxiolytic- and antidepressant-like effects in mice. Neuropsychopharmacology 31, 2405-2414.

Bredy, T. W., Humpartzoomian, R. A., Cain, D. P., and Meaney, M. J. (2003). Partial reversal of the effect of maternal care on cognitive function through environmental enrichment. Neuroscience 118, 571-576.

Bredy, T. W., Zhang, T. Y., Grant, R. J., Diorio, J., and Meaney, M. J. (2004). Peripubertal environmental enrichment reverses the effects of maternal care on hippocampal development and glutamate receptor subunit expression. Eur. J. Neurosci. 20, 1355-1362.

Brigman, J. L., Wright, T., Talani, G., Prasad-Mulcare, S., Jinde, S., Seabold, G. K., Mathur, P., Davis, M. I., Bock, R., Gustin, R. M., Colbran, R. J., Alvarez, V. A., Nakazawa, K., Delpire, E., Lovinger, D. M., and Holmes, A. (2010). Loss of GluN2Bcontaining NMDA receptors in CA1 Hippocampus and cortex impairs long-term depression, reduces dendritic spine density, and disrupts learning. J. Neurosci. 30, 4590-4600.

Brummelte, S., and Galea, L. A. (2010). Chronic high corticosterone reduces neurogenesis in the dentate gyrus of adult male and female rats. Neuroscience 168, 680-690.

Butters, M. A., Becker, J. T., Nebes, R. D., Zmuda, M. D., Mulsant, B. H., Pollock, B. G., and Reynolds, C. F. III. (2000). Changes in cognitive functioning following treatment of late-life depression. Am. J. Psychiatry 157, 1949-1954.

Caldji, C., Tannenbaum, B., Sharma, S., Francis, D., Plotsky, P. M., and Meaney, M. J. (1998). Maternal care during infancy regulates the development of neural systems mediating the expression of fearfulness in the rat. Proc. Natl. Acad. Sci. U.S.A. 95, 5335-5340.

Champagne, D. L., Bagot, R. C., van, H F., Ramakers, G., Meaney, M. J., de Kloet, E. R., Joels, M., and Krugers, H. (2008). Maternal care and hippocampal plasticity: evidence for experience-dependent structural plasticity, altered synaptic functioning, and differential responsiveness to glucocorticoids and stress. J. Neurosci. 28, 6037-6045.

Champagne, F. A., Francis, D. D. Mar, A., and Meaney, M. J. (2003). Variations in maternal care in the rat as a mediating influence for the effects of environment on development. Physiol. Behav. 79, 359-371.

Chaouloff, F., Hemar, A., and Manzoni, O. (2008). Local facilitation of hippocampal metabotropic glutamate receptordependent long-term depression by corticosterone and dexamethasone. Psychoneuroendocrinology 33, 686-691.

Chatterton, J. E., Awobuluyi, M., Premkumar, L. S., Takahashi, H., Talantova, M., Shin, Y., Cui, J., Tu, S., Sevarino, K. A., Nakanishi, N., Tong, G., Lipton, S. A., and Zhang, D. (2002). Excitatory glycine receptors containing the NR3 family of NMDA receptor subunits. Nature 415, 793-798.

Chen, C. C., Yang, C. H., Huang, C. C., and Hsu, K. S. (2010). Acute stress impairs hippocampal mossy fiber-CA3 long-term potentiation by enhancing cAMP-specific phosphodiesterase 4 activity. Neuropsychopharmacology 35, 1605-1617.

Choi, D. W. (1988). Glutamate neurotoxicity and diseases of the nervous system. Neuron 1, 623-634.

Christian, K. M., Miracle, A. D., Wellman, C. L., and Nakazawa, K. (2011). Chronic stress-induced hippocampal dendritic retraction requires CA3 NMDA receptors. Neuroscience 174, 26-36.

Ciabarra, A. M., Sullivan, J. M., Gahn, L. G., Pecht, G., Heinemann, S., and Sevarino, K. A. (1995). Cloning and characterization of chi-1: a developmentally regulated member of a novel class of the ionotropic glutamate receptor family. J. Neurosci. 15 , 6498-6508.

Coan, E. J., Irving, A. J., and Collingridge, G. L. (1989). Lowfrequency activation of the NMDA receptor system can prevent the induction of LTP. Neurosci. Lett. 105, 205-210.

Collingridge, G. L., Isaac, J. T., and Wang, Y. T. (2004). Receptor trafficking and synaptic plasticity. Nat. Rev. Neurosci. 5, 952-962.

Collingridge, G. L., Kehl, S. J., and McLennan, H. (1983). Excitatory amino acids in synaptic transmission in the Schaffer collateralcommissural pathway of the rat hippocampus. J. Physiol. 334, 33-46.

Conrad, C. D., Galea, L. A., Kuroda, Y., and McEwen, B. S. (1996). Chronic stress impairs rat spatial memory on the Y maze, and this effect is blocked by tianeptine pretreatment. Behav. Neurosci. 110, 1321-1334.

Cui, B., Wu, M., and She, X. (2009). Effects of chronic noise exposure on spatial learning and memory of rats in relation to neurotransmitters and NMDAR2B alteration in the hippocampus. J. Occup. Health 51, 152-158.

Dallman, M. F., and Yates, F. E. (1969). Dynamic asymmetries in the corticosteroid feedback path and distribution-metabolism-binding elements of the adrenocortical system. Ann. N.Y. Acad. Sci. 156, 696-721.

Debanne, D., Guerineau, N. C., Gahwiler, B. H., and Thompson, S. M. (1996). Paired-pulse facilitation and depression at unitary synapses in rat hippocampus: quantal fluctuation affects subsequent release. J. Physiol. 491(Pt 1), 163-176.

de Kloet, E. R., Vreugdenhil, E., Oitzl, M. S., and Joels, M. (1998). Brain corticosteroid receptor balance in health and disease. Endocr. Rev. 19, 269-301.

Diamond, D. M., Bennett, M. C., Fleshner, M., and Rose, G. M. (1992). Inverted-U relationship between the level of peripheral corticosterone and the magnitude of hippocampal primed burst potentiation. Hippocampus 2, 421-430.

Diamond, D. M., Fleshner, M. Ingersoll, N., and Rose, G. M. (1996). Psychological stress impairs spatial working memory: relevance to electrophysiological studies of hippocampal function. Behav. Neurosci. 110, 661-672.

Dingledine, R., Borges, K., Bowie, D., and Traynelis, S. F. (1999). The glutamate receptor ion channels. Pharmacol. Rev. 51, 7-61.

Dolorfo, C. L., and Amaral, D. G. (1998). Entorhinal cortex of the rat: topographic organization of the cells of origin of the perforant path projection to the dentate gyrus. J. Comp. Neurol. 398, 25-48.

Droste, S. K., de, G. L., Atkinson, H. C., Lightman, S. L., Reul, J. M., and Linthorst, A. C. (2008). Corticosterone levels in the brain 
show a distinct ultradian rhythm but a delayed response to forced swim stress. Endocrinology 149, 3244-3253.

Droste, S. K., de, G. L., Lightman, S. L., Reul, J. M., and Linthorst, A. C. (2009). The ultradian and circadian rhythms of free corticosterone in the brain are not affected by gender: an in vivo microdialysis study in Wistar rats. J. Neuroendocrinol. 21, 132-140.

Dudek, S. M., and Bear, M. F. (1992). Homosynaptic long-term depression in area CAl of hippocampus and effects of N-methyl-D-aspartate receptor blockade. Proc. Natl. Acad. Sci. U.S.A. 89, 4363-4367.

Dumas, T. C., Gillette, T., Ferguson, D., Hamilton, K., and Sapolsky, R. M. (2010). Anti-glucocorticoid gene therapy reverses the impairing effects of elevated corticosterone on spatial memory, hippocampal neuronal excitability, and synaptic plasticity. J. Neurosci. 30, 1712-1720.

Erisir, A., and Harris, J. L. (2003). Decline of the critical period of visual plasticity is concurrent with the reduction of NR2B subunit of the synaptic NMDA receptor in layer 4. J. Neurosci. 23, 5208-5218.

Erreger, K., Dravid, S. M., Banke, T. G., Wyllie, D. J., and Traynelis, S. F. (2005). Subunit-specific gating controls rat NR1/NR2A and NR1/NR2B NMDA channel kinetics and synaptic signalling profiles. J. Physiol. 563, 345-358.

Fetterolf, F., and Foster, K. A. (2011). Regulation of long-term plasticity induction by the channel and C-terminal domains of GluN2 subunits. Mol. Neurobiol. 44, 71-82.

Foster, K. A., McLaughlin, N., Edbauer, D., Phillips, M., Bolton, A., Constantine-Paton, M., and Sheng, M. (2010). Distinct roles of NR2A and NR2B cytoplasmic tails in long-term potentiation. J. Neurosci. 30, 2676-2685.

Francis, D., Diorio, J., Liu, D., and Meaney, M. J. (1999). Nongenomic transmission across generations of maternal behavior and stress responses in the rat. Science 286, 1155-1158.

Frankiewicz, T., and Parsons, C. G. (1999). Memantine restores long term potentiation impaired by tonic N-methyl-D-aspartate (NMDA) receptor activation following reduction of $\mathrm{Mg} 2+$ in hippocampal slices. Neuropharmacology 38, 1253-1259.

Furay, A. R., Bruestle, A. E., and Herman, J. P. (2008). The role of the forebrain glucocorticoid receptor in acute and chronic stress. Endocrinology 149, 5482-5490.

Ge, Y., Dong, Z., Bagot, R. C., Howland, J. G., Phillips, A. G., Wong, T. P., and Wang, Y. T. (2010). Hippocampal long-term depression is required for the consolidation of spatial memory. Proc. Natl. Acad. Sci. U.S.A. 107, 16697-16702.

Gerges, N. Z., Stringer, J. L., and Alkadhi, K. A. (2001). Combination of hypothyroidism and stress abolishes early LTP in the CA1 but not dentate gyrus of hippocampus of adult rats. Brain Res. 922, 250-260.

Gore, A. C., Yeung, G., Morrison, J. H., and Oung, T. (2000). Neuroendocrine aging in the female rat: the changing relationship of hypothalamic gonadotropinreleasing hormone neurons and $\mathrm{N}$-methyl-D-aspartate receptors. Endocrinology 141, 4757-4767.

Groc, L., Choquet, D., and Chaouloff, F. (2008). The stress hormone corticosterone conditions AMPAR surface trafficking and synaptic potentiation. Nat. Neurosci. 11, 868-870.

Groc, L., Heine, M., Cognet, L., Brickley, K., Stephenson, F. A., Lounis, B., and Choquet, D. (2004). Differential activity-dependent regulation of the lateral mobilities of AMPA and NMDA receptors. Nat. Neurosci. 7, 695-696.

Groc, L., Heine, M., Cousins, S. L., Stephenson, F. A., Lounis, B., Cognet, L., and Choquet, D. (2006). NMDA receptor surface mobility depends on NR2A-2B subunits. Proc. Natl. Acad. Sci. U.S.A. 103, 18769-18774.

Groeneweg, F. L., Karst, H., de Kloet, E. R., and Joels, M. (2011). Rapid non-genomic effects of corticosteroids and their role in the central stress response. J. Endocrinol. 209, 153-167.

Grosshans, D. R., Clayton, D. A. Coultrap, S. J., and Browning, M. D. (2002). LTP leads to rapid surface expression of NMDA but not AMPA receptors in adult rat CA1. Nat. Neurosci. 5, 27-33.

Holderbach, R., Clark, K., Moreau, J. L., Bischofberger, J., and Normann, C. (2007). Enhanced long-term synaptic depression in an animal model of depression. Biol. Psychiatry 62, 92-100.

Hollmann, M., and Heinemann, S. (1994). Cloned glutamate receptors. Annu. Rev. Neurosci. 17, 31-108.

Huang, C. C., Chen, J. P., Yeh, C. M., and Hsu, K. S. Sex difference in stress-induced enhancement of hippocampal CA1 long-term depression during puberty. Hippocampus [Epub ahead of print].
Ikegaya, Y., and Matsuki, N. (2002). Regionally selective neurotoxicity of NMDA and colchicine is independent of hippocampal neural circuitry. Neuroscience 113, 253-256.

Ishii, T., Moriyoshi, K., Sugihara, H. Sakurada, K., Kadotani, H., Yokoi, M., Akazawa, C., Shigemoto, R., Mizuno, N., and Masu, M. (1993). Molecular characterization of the family of the N-methyl-D-aspartate receptor subunits. J. Biol. Chem. 268, 2836-2843.

Joels, M. (2001). Corticosteroid actions in the hippocampus. $J$. Neuroendocrinol. 13, 657-669.

Joels, M., and de Kloet, E. R. (1989). Effects of glucocorticoids and norepinephrine on the excitability in the hippocampus. Science 245 , 1502-1505.

Joels, M., Karst, H., Krugers, H. J. and Lucassen, P. J. (2007). Chronic stress: implications for neuronal morphology, function and neurogenesis. Front. Neuroendocrinol. 28, 72-96.

Johnson, L. R., Farb, C., Morrison, J. H., McEwen, B. S., and LeDoux, J. E. (2005). Localization of glucocorticoid receptors at postsynaptic membranes in the lateral amygdala. Neuroscience 136, 289-299.

Karst, H., Berger, S., Turiault, M. Tronche, F., Schutz, G., and Joels, M. (2005). Mineralocorticoid receptors are indispensable for nongenomic modulation of hippocampal glutamate transmission by corticosterone. Proc. Natl. Acad. Sci. U.S.A. 102, 19204-19207.

Karst, H., and Joels, M. (2005). Corticosterone slowly enhances miniature excitatory postsynaptic current amplitude in mice CA1 hippocampal cells. J. Neurophysiol. 94, 3479-3486.

Karst, H., Karten, Y. J., Reichardt, H. M., de Kloet, E. R., Schutz, G., and Joels, M. (2000). Corticosteroid actions in hippocampus require DNA binding of glucocorticoid receptor homodimers. Nat. Neurosci. 3, 977-978.

Katagiri, H., Tanaka, K., and Manabe, T. (2001). Requirement of appropriate glutamate concentrations in the synaptic cleft for hippocampal LTP induction. Eur. J. Neurosci. 14, 547-553.

Katz, B. (1971). Quantal mechanism of neural transmitter release. Science 173, 123-126.

Kerr, D. S., Huggett, A. M., and Abraham, W. C. (1994). Modulation of hippocampal long-term potentiation and long-term depression by corticosteroid receptor activation. Psychobiology 22, 123-133.
Kessler, R. C., Davis, C. G., and Kendler, K. S. (1997). Childhood adversity and adult psychiatric disorder in the US National Comorbidity Survey. Psychol. Med. 27, 1101-1119.

Kirson, E. D., and Yaari, Y. (1996). Synaptic NMDA receptors in developing mouse hippocampal neurones: functional properties and sensitivity to ifenprodil. J. Physiol. 497, 437-455.

Kitraki, E., Kremmyda, O., Youlatos, D., Alexis, M. N., and Kittas, C. (2004). Gender-dependent alterations in corticosteroid receptor status and spatial performance following 21 days of restraint stress. Neuroscience 125, 47-55.

Kohr, G., Jensen, V., Koester, H. J., Mihaljevic, A. L., Utvik, J. K., Kvello, A., Ottersen, O. P., Seeburg, P. H., Sprengel, R., and Hvalby, O. (2003). Intracellular domains of NMDA receptor subtypes are determinants for long-term potentiation induction. J. Neurosci. 23, 10791-10799.

Kole, M. H., Swan, L., and Fuchs, E. (2002). The antidepressant tianeptine persistently modulates glutamate receptor currents of the hippocampal CA3 commissural associational synapse in chronically stressed rats. Eur. J. Neurosci. 16, 807-816.

Korz, V., and Frey, J. U. (2003). Stress-related modulation of hippocampal long-term potentiation in rats: involvement of adrenal steroid receptors. J. Neurosci. 23, 7281-7287.

Krugers, H. J., Alfarez, D. N., Karst, H., Parashkouhi, K., van Gemert, N., and Joels, M. (2005). Corticosterone shifts different forms of synaptic potentiation in opposite directions. Hippocampus 15, 697-703.

Kutsuwada, T., Kashiwabuchi, N., Mori, H., Sakimura, K., Kushiya, E., Araki, K., Meguro, H., Masaki, H., Kumanishi, T., and Arakawa, M. (1992). Molecular diversity of the NMDA receptor channel. Nature 358, 36-41.

Laurie, D. J., Bartke, I., Schoepfer, R., Naujoks, K., and Seeburg, P. H. (1997). Regional, developmental and interspecies expression of the four NMDAR2 subunits, examined using monoclonal antibodies. Mol. Brain Res. 51, 23-32.

Li, N., Lee, B., Liu, R. J., Banasr, M. Dwyer, J. M., Iwata, M., Li, X. Y., Aghajanian, G., and Duman, R. S. (2010). mTOR-dependent synapse formation underlies the rapid antidepressant effects of NMDA antagonists. Science 329, 959-964.

Lindholm, J. S., Autio, H., Vesa, L., Antila, H., Lindemann, L., Hoener, 
M. C., Skolnick, P., Rantamaki, T., and Castren, E. (2012). The antidepressant-like effects of glutamatergic drugs ketamine and AMPA receptor potentiator LY 451646 are preserved in bdnf $(+/-)$ heterozygous null mice. Neuropharmacology 62, 391-397.

Liposits, Z., and Bohn, M. C. (1993). Association of glucocorticoid receptor immunoreactivity with cell membrane and transport vesicles in hippocampal and hypothalamic neurons of the rat. J. Neurosci. Res. $35,14-19$.

Liu, D., Diorio, J., Day, J. C., Francis, D. D., and Meaney, M. J. (2000). Maternal care, hippocampal synaptogenesis and cognitive development in rats. Nat. Neurosci. 3, 799-806.

Liu, D., Diorio, J., Tannenbaum, B., Caldji, C., Francis, D., Freedman, A., Sharma, S., Pearson, D., Plotsky, P. M., and Meaney, M. J. (1997). Maternal care, hippocampal glucocorticoid receptors, and hypothalamic-pituitary-adrenal responses to stress. Science 277, 1659-1662.

Liu, L., Wang, C., Ni, X., and Sun, J. (2007). A rapid inhibition of NMDA receptor current by corticosterone in cultured hippocampal neurons. Neurosci. Lett. 420, 245-250.

Liu, L., Wong, T. P., Pozza, M. F., Lingenhoehl, K., Wang, Y., Sheng, M., Auberson, Y. P., and Wang, Y. T. (2004). Role of NMDA receptor subtypes in governing the direction of hippocampal synaptic plasticity. Science 304, 1021-1024.

Liu, P., Smith, P. F., and Darlington, C. L. (2008). Glutamate receptor subunits expression in memoryassociated brain structures: regional variations and effects of aging. Synapse 62, 834-841.

Luine, V. N., Beck, K. D., Bowman, R. E., Frankfurt, M., and MacLusky, N. J. (2007). Chronic stress and neural function: accounting for sex and age. J. Neuroendocrinol. 19, 743-751.

Ma, W. P., Cao, J., Tian, M., Cui, M. H., Han, H. L., Yang, Y. X., and $\mathrm{Xu}, \mathrm{L}$. (2007). Exposure to chronic constant light impairs spatial memory and influences longterm depression in rats. Neurosci. Res. 59, 224-230.

MacDermott, A. B., Mayer, M. L., Westbrook, G. L., Smith, S. J., and Barker, J. L. (1986). NMDAreceptor activation increases cytoplasmic calcium concentration in cultured spinal cord neurones. Nature 321, 519-522.

Machado-Vieira, R., Yuan, P., Brutsche, N., Diazgranados, N., Luckenbaugh,
D., Manji, H. K., and Zarate, C. A. Jr. (2009). Brain-derived neurotrophic factor and initial antidepressant response to an $\mathrm{N}$-methyl-D-aspartate antagonist. J. Clin. Psychiatry 70, 1662-1666.

Magarinos, A. M., and McEwen, B. S. (1995). Stress-induced atrophy of apical dendrites of hippocampal CA3c neurons: involvement of glucocorticoid secretion and excitatory amino acid receptors. Neuroscience 69, 89-98.

Maggio, N., and Segal, M. (2007). Striking variations in corticosteroid modulation of long-term potentiation along the septotemporal axis of the hippocampus. J. Neurosci. 27, 5757-5765.

Maggio, N., and Segal, M. (2009). Differential modulation of longterm depression by acute stress in the rat dorsal and ventral hippocampus. J. Neurosci. 29, 8633-8638.

Malenka, R. C. (2003). Synaptic plasticity and AMPA receptor trafficking. Ann. N.Y. Acad. Sci. 1003, 1-11.

Malinow, R., and Malenka, R. C. (2002). AMPA receptor trafficking and synaptic plasticity. Annu. Rev. Neurosci. 25, 103-126.

Martin, S., Henley, J. M., Holman, D., Zhou, M., Wiegert, O., van, S. M., Joels, M., Hoogenraad, C. C., and Krugers, H. J. (2009). Corticosterone alters AMPAR mobility and facilitates bidirectional synaptic plasticity. PLoS One 4:e4714. doi: 10.1371/journal. pone. 0004714

Martin, S. J., Grimwood, P. D., and Morris, R. G. (2000). Synaptic plasticity and memory: an evaluation of the hypothesis. Annu. Rev. Neurosci. 23, 649-711.

McEwen, B. S. (1999). Stress and hippocampal plasticity. Annu. Rev. Neurosci. 22, 105-122.

McEwen, B. S., and Sapolsky, R. M. (1995). Stress and cognitive function. Curr. Opin. Neurobiol. 5, 205-216.

McHugh, S. B., Deacon, R. M., Rawlins, J. N., and Bannerman, D. M. (2004). Amygdala and ventral hippocampus contribute differentially to mechanisms of fear and anxiety. Behav. Neurosci. 118, 63-78.

McLaughlin, K. A., Green, J. G., Gruber, M. J., Sampson, N. A., Zaslavsky, A. M., and Kessler, R. C. (2010). Childhood adversities and adult psychiatric disorders in the national comorbidity survey replication II: associations with persistence of DSM-IV disorders. Arch. Gen. Psychiatry 67, 124-132.
Meaney, M. J., Aitken, D. H., Bodnoff, S. R., Iny, L. J., and Sapolsky, R. M. (1985). The effects of postnatal handling on the development of the glucocorticoid receptor systems and stress recovery in the rat. Prog. Neuropsychopharmacol. Biol. Psychiatry 9, 731-734.

Meguro, H., Mori, H., Araki, K. Kushiya, E., Kutsuwada, T., Yamazaki, M., Kumanishi, T., Arakawa, M., Sakimura, K., and Mishina, M. (1992). Functional characterization of a heteromeric NMDA receptor channel expressed from cloned cDNAs. Nature 357, 70-74.

Meltzer, H. Y., and McGurk, S. R. (1999). The effects of clozapine, risperidone, and olanzapine on cognitive function in schizophrenia. Schizophr. Bull. 25, 233-255.

Monyer, H., Burnashev, N., Laurie, D. J., Sakmann, B., and Seeburg, P. H. (1994). Developmental and regional expression in the rat brain and functional properties of four NMDA receptors. Neuron 12, 529-540.

Monyer, H., Sprengel, R., Schoepfer, R., Herb, A., Higuchi, M., Lomeli, H., Burnashev, N., Sakmann, B., and Seeburg, P. H. (1992). Heteromeric NMDA receptors: molecular and functional distinction of subtypes. Science 256, 1217-1221.

Morano, M. I., Vazquez, D. M., and Akil, H. (1994). The role of the hippocampal mineralocorticoid and glucocorticoid receptors in the hypothalamo-pituitary-adrenal axis of the aged Fisher rat. Mol. Cell. Neurosci. 5, 400-412.

Moriyoshi, K., Masu, M., Ishii, T., Shigemoto, R., Mizuno, N., and Nakanishi, S. (1991). Molecular cloning and characterization of the rat NMDA receptor. Nature 354, 31-37.

Moser, E., Moser, M. B., and Andersen, P. (1993). Spatial learning impairment parallels the magnitude of dorsal hippocampal lesions, but is hardly present following ventral lesions. J. Neurosci. 13, 3916-3925.

Muller, D., Joly, M., and Lynch, G. (1988). Contributions of quisqualate and NMDA receptors to the induction and expression of LTP. Science 242, 1694-1697.

Muscatell, K. A., Slavich, G. M., Monroe, S. M., and Gotlib, I. H. (2009). Stressful life events, chronic difficulties, and the symptoms of clinical depression. J. Nerv. Ment. Dis. 197, 154-160.

Nakanishi, S. (1992). Molecular diversity of glutamate receptors and implications for brain function. Science 258, 597-603.
Nowak, L., Bregestovski, P., Ascher, P., Herbet, A., and Prochiantz, A. (1984). Magnesium gates glutamate-activated channels in mouse central neurones. Nature 307, 462-465.

Olijslagers, J. E., de Kloet, E. R., Elgersma, Y., van Woerden, G. M., Joels, M., and Karst, H. (2008). Rapid changes in hippocampal CA1 pyramidal cell function via preas well as postsynaptic membrane mineralocorticoid receptors. Eur. J. Neurosci. 27, 2542-2550.

Palomero-Gallagher, N., Bidmon, H. J., and Zilles, K. (2003). AMPA, kainate, and NMDA receptor densities in the hippocampus of untreated male rats and females in estrus and diestrus. J. Comp. Neurol. 459, 468-474.

Pandis, C., Sotiriou, E., Kouvaras, E. Asprodini, E., Papatheodoropoulos, C., and Angelatou, F. (2006). Differential expression of NMDA and AMPA receptor subunits in rat dorsal and ventral hippocampus. Neuroscience 140, 163-175.

Papatheodoropoulos, C. (2007). NMDA receptor-dependent highfrequency network oscillations $(100-300 \mathrm{~Hz})$ in rat hippocampal slices. Neurosci. Lett. 414, 197-202.

Pasricha, N., Joels, M., and Karst, H. (2011). Rapid effects of corticosterone in the mouse dentate gyrus via a nongenomic pathway. J. Neuroendocrinol. 23, 143-147.

Pavlides, C., Kimura, A., Magarinos, A. M., and McEwen, B. S. (1994) Type I adrenal steroid receptors prolong hippocampal long-term potentiation. Neuroreport 5, 2673-2677.

Pavlides, C., Kimura, A., Magarinos, A. M., and McEwen, B. S. (1995). Hippocampal homosynaptic longterm depression/depotentiation induced by adrenal steroids. Neuroscience 68, 379-385.

Pavlides, C., Nivon, L. G., and McEwen, B. S. (2002). Effects of chronic stress on hippocampal long-term potentiation. Hippocampus 12, 245-257.

Pavlides, C., Ogawa, S., Kimura, A., and McEwen, B. S. (1996). Role of adrenal steroid mineralocorticoid and glucocorticoid receptors in long-term potentiation in the CA1 field of hippocampal slices. Brain Res. 738, 229-235.

Perkel, D. J., and Nicoll, R. A. (1993). Evidence for all-or-none regulation of neurotransmitter release: implications for long-term potentiation. J. Physiol. 471, 481-500.

Petralia, R. S., Esteban, J. A., Wang, Y. X., Partridge, J. G., Zhao, H. M., Wenthold, R. J., and Malinow, R. (1999). Selective acquisition of 
AMPA receptors over postnatal development suggests a molecular basis for silent synapses. Nat. Neurosci. 2, 31-36.

Pitkanen, A., Pikkarainen, M. Nurminen, N., and Ylinen, A. (2000). Reciprocal connections between the amygdala and the hippocampal formation, perirhinal cortex, and postrhinal cortex in rat. A review. Ann. N.Y. Acad. Sci. 911, 369-391.

Pittenger, C., Sanacora, G., and Krystal, J. H. (2007). The NMDA receptor as a therapeutic target in major depressive disorder. CNS Neurol. Disord. Drug Targets 6, 101-115.

Prager, E. M., and Johnson, L. R. (2009). Stress at the synapse: signal transduction mechanisms of adrenal steroids at neuronal membranes. Sci. Signal. 2, re5.

Qi, A. Q., Qiu, J., Xiao, L., and Chen, Y. Z. (2005). Rapid activation of JNK and p38 by glucocorticoids in primary cultured hippocampal cells. J. Neurosci. Res. 80, 510-517.

Qin, Y., Karst, H., and Joels, M. (2004). Chronic unpredictable stress alters gene expression in rat single dentate granule cells. J. Neurochem. 89 , 364-374.

Rebola, N., Carta, M., Lanore, F., Blanchet, C., and Mulle, C. (2011). NMDA receptor-dependent metaplasticity at hippocampal mossy fiber synapses. Nat. Neurosci. 14, 691-693.

Reul, J. M., and de Kloet, E. R. (1985). Two receptor systems for corticosterone in rat brain: microdistribution and differential occupation. Endocrinology 117, 2505-2511.

Rey, M., Carlier, E., Talmi, M., and Soumireu-Mourat, B. (1994). Corticosterone effects on long-term potentiation in mouse hippocampal slices. Neuroendocrinology 60, 36-41.

Richmond, M. A., Yee, B. K., Pouzet, B., Veenman, L., Rawlins, J. N., Feldon, J., and Bannerman, D. M. (1999). Dissociating context and space within the hippocampus: effects of complete, dorsal, and ventral excitotoxic hippocampal lesions on conditioned freezing and spatial learning. Behav. Neurosci. 113, 1189-1203.

Riedemann, T., Patchev, A. V., Cho, K., and Almeida, O. F. (2010). Corticosteroids: way upstream. Mol. Brain 3, 2.

Ritter, L. M., Vazquez, D. M., and Meador-Woodruff, J. H. (2002). Ontogeny of ionotropic glutamate receptor subunit expression in the rat hippocampus. Brain Res. Dev. Brain Res. 139, 227-236.
Robertson, D. A., Beattie, J. E., Reid, I. C., and Balfour, D. J. (2005). Regulation of corticosteroid receptors in the rat brain: the role of serotonin and stress. Eur. J. Neurosci. 21, 1511-1520.

Roozendaal, B., Hernandez, A. Cabrera, S. M., Hagewoud, R., Malvaez, M., Stefanko, D. P., Haettig, J., and Wood, M. A. (2010) Membrane-associated glucocorticoid activity is necessary for modulation of long-term memory via chromatin modification. J. Neurosci. 30, 5037-5046.

Sandi, C., and Pinelo-Nava, M. T. (2007). Stress and memory: behavioral effects and neurobiological mechanisms. Neural Plast. 2007, 78970.

Sapolsky, R. M. (2000). Glucocorticoids and hippocampal atrophy in neuropsychiatric disorders. Arch. Gen. Psychiatry 57, 925-935.

Sapolsky, R. M., Romero, L. M., and Munck, A. U. (2000). How do glucocorticoids influence stress responses? Integrating permissive, suppressive, stimulatory, and preparative actions. Endocr. Rev. 21, 55-89.

Sato, S., Osanai, H., Monma, T., Harada, T., Hirano, A., Saito, M., and Kawato, S. (2004). Acute effect of corticosterone on N-methyl-Daspartate receptor-mediated $\mathrm{Ca} 2+$ elevation in mouse hippocampal slices. Biochem. Biophys. Res. Commun. 321, 510-513.

Schanberg, S. M., Evoniuk, G., and Kuhn, C. M. (1984). Tactile and nutritional aspects of maternal care: specific regulators of neuroendocrine function and cellular development. Proc. Soc. Exp. Biol. Med. 175, 135-146.

Seeburg, P. H. (1993). The TINS/TiPS Lecture. The molecular biology of mammalian glutamate receptor channels. Trends Neurosci. 16, 359-365.

Sheng, M., Cummings, J., Roldan, L. A., Jan, Y. N., and Jan, L. Y. (1994). Changing subunit composition of heteromeric NMDA receptors during development of rat cortex. Nature 368, 144-147.

Singh, T. D., Heinrich, J. E., Wissman, A. M., Brenowitz, E. A., Nordeen, E. J., and Nordeen, K. W. (2003). Seasonal regulation of NMDA receptor NR2B mRNA in the adult canary song system. J. Neurobiol. 54, 593-603.

Skolnick, P., Popik, P., and Trullas, R. (2009). Glutamate-based antidepressants: 20 years on. Trends Pharmacol. Sci. 30, 563-569.
Statistics Canada. (2002). Life stress, by age group and sex, household population aged 18 and over, Canada, 2000/01. Health Indic. 2002, 1-2.

Sucher, N. J., Akbarian, S., Chi, C. L., Leclerc, C. L., Awobuluyi, M. Deitcher, D. L., Wu, M. K., Yuan, J. P., Jones, E. G., and Lipton S. A. (1995). Developmental and regional expression pattern of a novel NMDA receptor-like subunit (NMDAR-L) in the rodent brain. J. Neurosci. 15, 6509-6520.

Swanson, L. W., and Cowan, W. M. (1977). An autoradiographic study of the organization of the efferent connections of the hippocampal formation in the rat. J. Comp. Neurol. 172, 49-84.

Takahashi, T., Kimoto, T., Tanabe, N. Hattori, T. A., Yasumatsu, N., and Kawato, S. (2002). Corticosterone acutely prolonged N-methyl-daspartate receptor-mediated $\mathrm{Ca} 2+$ elevation in cultured rat hippocampal neurons. J. Neurochem. 83, 1441-1451.

Taniguchi, S., Nakazawa, T., Tanimura, A., Kiyama, Y., Tezuka, T., Watabe A. M., Katayama, N., Yokoyama, K., Inoue, T., Izumi-Nakaseko, H., Kakuta, S., Sudo, K., Iwakura, Y., Umemori, H., Inoue, T., Murphy, N. P., Hashimoto, K., Kano, M. Manabe, T., and Yamamoto, T. (2009). Involvement of NMDAR2A tyrosine phosphorylation in depression-related behaviour. EMBO J. 28 3717-3729.

Tovar, K. R., and Westbrook, G. L. (2002). Mobile NMDA receptors at hippocampal synapses. Neuron 34 255-264.

Tsai, M. J., and O'Malley, B. W. (1994). Molecular mechanisms of action of steroid/thyroid receptor superfamily members. Annu. Rev. Biochem. 63, 451-486.

Tse, Y. C., Bagot, R. C., Hutter, J. A. Wong, A. S., and Wong, T. P. (2011). Modulation of synaptic plasticity by stress hormone associates with plastic alteration of synaptic NMDA receptor in the adult hippocampus. PLoS One 6:e27215. doi: 10.1371/journal.pone.0027215

Vaher, P. R., Luine, V. N., Gould, E., and McEwen, B. S. (1994) Effects of adrenalectomy on spatial memory performance and dentate gyrus morphology. Brain Res. 656, 71-78.

Van Eekelen, J. A., Jiang, W., de Kloet, E. R., and Bohn, M. C. (1988). Distribution of the mineralocorticoid and the glucocorticoid receptor mRNAs in the rat hippocampus. J. Neurosci. Res. 21, 88-94.
Van Gemert, N. G., Carvalho, D. M., Karst, H., van der Laan, S., Zhang, M., Meijer, O. C., Hell, J. W., and Joels, M. (2009). Dissociation between rat hippocampal CA1 and dentate gyrus cells in their response to corticosterone: effects on calcium channel protein and current. Endocrinology 150, 4615-4624.

Van, G. T., and Wyss, J. M. (1990). Extrinsic projections from area CA1 of the rat hippocampus: olfactory, cortical, subcortical, and bilateral hippocampal formation projections. J. Comp. Neurol. 302, 515-528.

Vanitallie, T. B. (2002). Stress: a risk factor for serious illness. Metabolism 51, 40-45.

Varela, J. A., Hirsch, S. J., Chapman, D., Leverich, L. S., and Greene, R. W. (2009). D1/D5 modulation of synaptic NMDA receptor currents. J. Neurosci. 29, 3109-3119.

Velisek, L., Slamberova, R., and Vathy, I. (2003). Prenatal morphine exposure suppresses mineralocorticoid receptor-dependent basal synaptic transmission and synaptic plasticity in the lateral perforant path in adult male rats. Brain Res. Bull. 61, 571-576.

Velisek, L., and Vathy, I. (2005). Mifepristone (RU486) inhibits lateral perforant path long-term potentiation in hippocampal slices from prenatally morphine-exposed female rats. Int. J. Dev. Neurosci. 23, 559-565.

Venero, C., and Borrell, J. (1999). Rapid glucocorticoid effects on excitatory amino acid levels in the hippocampus: a microdialysis study in freely moving rats. Eur. J. Neurosci. 11, 2465-2473.

Viau, V., Sharma, S., Plotsky, P. M., and Meaney, M. J. (1993). Increased plasma ACTH responses to stress in nonhandled compared with handled rats require basal levels of corticosterone and are associated with increased levels of ACTH secretagogues in the median eminence. J. Neurosci. 13, 1097-1105.

Watanabe, Y., Gould, E., and McEwen, B. S. (1992). Stress induces atrophy of apical dendrites of hippocampal CA3 pyramidal neurons. Brain Res. 588, 341-345.

Weaver, I. C., Cervoni, N., Champagne, F. A., D'Alessio, A. C., Sharma, S., Seckl, J. R., Dymov, S., Szyf, M., and Meaney, M. J. (2004). Epigenetic programming by maternal behavior Nat. Neurosci. 7, 847-854.

Weaver, I. C., Champagne, F. A., Brown, S. E., Dymov, S., Sharma, S., Meaney, M. J., and Szyf, M. (2005). Reversal of maternal programming 
of stress responses in adult offspring through methyl supplementation: altering epigenetic marking later in life. J. Neurosci. 25, 11045-11054.

Wenzel, A., Fritschy, J. M., Mohler, H., and Benke, D. (1997). NMDA receptor heterogeneity during postnatal development of the rat brain: differential expression of the NR2A, NR2B, and NR2C subunit proteins. J. Neurochem. 68, 469-478.

Wiegert, O., Joels, M., and Krugers, H. (2006). Timing is essential for rapid effects of corticosterone on synaptic potentiation in the mouse hippocampus. Learn. Mem. 13, 110-113.

Wiegert, O., Pu, Z., Shor, S., Joels, M., and Krugers, H. (2005). Glucocorticoid receptor activation selectively hampers N-methylD-aspartate receptor dependent hippocampal synaptic plasticity in vitro. Neuroscience 135, 403-411.

Woolley, C. S., Gould, E., and McEwen, B. S. (1990). Exposure to excess glucocorticoids alters dendritic morphology of adult hippocampal pyramidal neurons. Brain Res. 531, 225-231.

Xiao, L., Feng, C., and Chen, Y. (2010). Glucocorticoid rapidly enhances NMDA-evoked neurotoxicity by attenuating the NR2A-containing NMDA receptor-mediated ERK1/2 activation. Mol. Endocrinol. 24, 497-510.

$\mathrm{Xu}, \mathrm{L} .$, Anwyl, R., and Rowan, M. J. (1997). Behavioural stress facilitates the induction of long-term depression in the hippocampus. Nature 387, 497-500.

$\mathrm{Xu}$, L., Holscher, C., Anwyl, R., and Rowan, M. J. (1998). Glucocorticoid receptor and protein/RNA synthesis-dependent mechanisms underlie the control of synaptic plasticity by stress. Proc. Natl. Acad. Sci. U.S.A. 95, 3204-3208.

Yang, C. H., Huang, C. C., and Hsu, K. S. (2005). Behavioral stress enhances hippocampal CA1 longterm depression through the blockade of the glutamate uptake. J. Neurosci. 25, 4288-4293.

Yang, J., Han, H., Cao, J., Li, L., and Xu, L. (2006). Prenatal stress modifies hippocampal synaptic plasticity and spatial learning in young rat offspring. Hippocampus 16 , 431-436.

Yang, J., Hou, C., Ma, N., Liu, J., Zhang, Y., Zhou, J., Xu, L., and Li, L. (2007). Enriched environment treatment restores impaired hippocampal synaptic plasticity and cognitive deficits induced by prenatal chronic stress. Neurobiol. Learn. Mem. 87, 257-263.

Yashiro, K., and Philpot, B. D. (2008). Regulation of NMDA receptor subunit expression and its implications for LTD, LTP, and metaplasticity. Neuropharmacology 55, 1081-1094.

Yuen, E. Y., Liu, W., Karatsoreos, I. N., Feng, J., McEwen, B. S., and Yan, Z. (2009). Acute stress enhances glutamatergic transmission in prefrontal cortex and facilitates working memory. Proc. Natl. Acad. Sci. U.S.A. 106, 14075-14079.

Yuen, E. Y., Liu, W., Karatsoreos, I. N., Ren, Y., Feng, J., McEwen, B. S., and Yan, Z. (2011). Mechanisms for acute stress-induced enhancement of glutamatergic transmission and working memory. Mol. Psychiatry 16, 156-170.

Conflict of Interest Statement: The authors declare that the research was conducted in the absence of any commercial or financial relationships that could be construed as a potential conflict of interest.

Received: 15 November 2011; accepted: 17 February 2012; published online: 06 March 2012.

Citation: Tse Y, Bagot RC and Wong T (2012) Dynamic regulation of NMDAR function in the adult brain by the stress hormone corticosterone. Front. Cell. Neurosci. 6:9. doi: 10.3389/fncel. 2012.00009

Copyright (c) 2012 Tse, Bagot and Wong. This is an open-access article distributed under the terms of the Creative Commons Attribution Non Commercial License, which permits non-commercial use, distribution, and reproduction in other forums, provided the original authors and source are credited. 